HStud 26 (2012)1, 45-66

DOI: 10.1556/HStud.26.2012.1.5

\title{
RHETORISCHE UND LITERATURSOZIOLOGISCHE BESONDERHEITEN UNGARISCHER DEDIKATIONSPRAXIS IM 17. JAHRHUNDERT
}

\author{
BRIGITTA PESTI \\ Universität Wien \\ Österreich
}

\begin{abstract}
Die Studie hat den Gesamtkorpus der ungarischen Buchproduktion zwischen 1600 und 1655 zum Gegenstand, um die Gattung der Dedikation analysieren zu können. Anhand der 338 untersuchten Werke wird ein detailliertes Bild der paratextuellen Gattung in ihren rhetorischen, topos-historischen und dichtungstheoretischen $\mathrm{Zu}$ sammenhängen gezeichnet, sowie das literarische Mäzenatentum der Frühen Neuzeit in Ungarn beschrieben. Neben der Analyse rhetorischer und literatursoziologischer Spezifika von einzelnen Dedikationen wird eine umfassende theoretische und historische Gattungsanalyse aufgestellt. Die Forschungsergebnisse werden mit Bezug auf bestehende Untersuchungen der englischen, deutschen und französischen Literatur in einen internationalen Kontext gestellt, so können die Besonderheiten der ungarischen paratextuellen Gattung und der Patronage festgestellt und analysiert werden.
\end{abstract}

Schlagwörter: Ungarische Literatur, Paratext, Dedikation, Mäzenatentum, Rhetorik, Topos, 17. Jahrhundert

Zwischen 1600 und 1655 sind in Ungarn nach dem Verzeichnis Alter Ungarischer Drucke (RMNy II und III.) ${ }^{1}$ etwa 1684 Bücher erschienen, davon 610, also etwa 36 Prozent mit Dedikationsbriefen. Was, wie, wem und warum wurde dediziert? Die Geschichte und Entwicklung der Buchwidmung ist lang, wechselvoll und in wesentlichen Teilen - besonders was die ungarische Literatur betrifft - noch $\mathrm{zu}$ schreiben. Anhand einer widmungsgeschichtlichen Forschung kann man die gattungsspezifischen Eigenschaften der barocken Paratexte, sowie die historisch-politischen und sozialen Zusammenhänge feststellen, die sich der Entstehungsgeschichte und den hypotextuellen Zusammenhängen einzelner Werke annähern. Nicht zuletzt ermöglicht sie eine ausführliche Analyse der literarischen Patronage der Zeit.

Die Dedikation, die symbolische Darbringung eines Buches ist in der Frühen Neuzeit fester Bestandteil der Buchausgabe. Im späten Mittelalter und zum großen Teil auch in der Frühen Neuzeit wurden die Bücher in Ungarn von Schriftstellern zwar selbst herausgegeben, allerdings nicht auf eigene Kosten. ${ }^{2}$ Diese wur- 
den zum größten Teil von Mäzenen getragen. In einem Druck ist traditionell die Dedikation - selten auch die Vorrede - der einzige Textraum, der dem Autor die Möglichkeit bietet, den Patron anzusprechen und (Selbst)Reflexionen über den Text zu liefern. Über seine Person können - ausgenommen in wenigen Fällen, in denen Einzelheiten der Patronage in Korrespondenzen nachweisbar sind - ausschließlich literarische Rahmentexte, wie das Titelblatt, die Vorrede und vor allem die Dedikation Auskunft geben. Dedikationen sind also grundlegende Quellen zur Literatursoziologie des Barock: Beziehungen zwischen Schriftsteller und Mäzen sowie Formen und Modus der Unterstützung bilden historisch betrachtet die Entwicklung der künstlerischen Unabhängigkeit ab.

\section{Forschungsstand und Fragestellung}

Das wissenschaftliche Interesse für Paratexte, also für Rahmentexte eines Buches, ist keine neue Erscheinung. Nicht nur Paratext-Sammlungen von bekannten Schriftstellern erschienen bereits am Anfang des 18. Jahrhunderts, ${ }^{3}$ sondern auch die ersten lateinsprachigen Studien über das Mäzenatentum der antiken Literatur und über die Geschichte der Dedikationen. ${ }^{4}$ Seit der umfassenden theoretischen Arbeit von Gérard Genette aus dem Jahr 1987 wurde die Paratextforschung zu einem wichtigen Bestandteil des literaturtheoretischen Diskurses. ${ }^{5}$ In der neuesten literaturtheoretischen Forschung wird die rezeptionslenkende Rolle der Paratexte $^{6}$ sowie deren Zusammenhang zu Derridas Begriff parergon ${ }^{7}$ untersucht. $^{8}$ Traditionell werden Paratexte allerdings vor allem als historische und literatursoziologische Quellen interpretiert. Die wichtigsten umfassenden Untersuchungen über die mittelalterlichen und frühneuzeitlichen Dedikationen der deutschsprachigen Literatur stammen von Karl Schottenloher ${ }^{9}$ und neulich von Gabriella Schramm, ${ }^{10}$ der französischsprachigen Literatur von Wolfgang Leiner ${ }^{11}$ und Sharon Kettering, ${ }^{12}$ der italienischen von Marco Paoli ${ }^{13}$ und der englischsprachigen unter anderem von Kevin Dunn ${ }^{14}$ und Dustin Griffin. ${ }^{15}$

Die ungarische Forschung konzentrierte sich bisher eher auf einzelne Gattungen oder Autoren. So untersucht zum Beispiel Emil Hargittay die Literaturauffassung von Péter Pázmány anhand seiner Paratexte, ${ }^{16} \mathrm{Csaba}$ Onder die Paratexte der ungarischen Gedichtsammlung aus dem 18. Jahrhundert, ${ }^{17}$ und János Heltai die Patronage der Erbauungsbücher und religiösen Streitschriften im Zusammenhang mit der Buchproduktion des 17. Jahrhunderts. Übergreifende Studien zu literaturtheoretischen oder literaturhistorischen Perspektiven des Paratextes wurden bisher nicht durchgeführt.

Diese Forschung will an den grob beschriebenen internationalen Diskurs anknüpfen und hat die gesamte ungarischsprachige Buchproduktion der ersten Hälfte des 17. Jahrhunderts (1600-1655) zum Gegenstand, um die Gattung der Dedi- 
kation analysieren zu können. Es werden einerseits die rhetorischen und literatursoziologischen Spezifika der einzelnen Werke dargestellt, andererseits wird anhand des gesamten Korpus eine umfassende theoretische und historische Gattungsanalyse aufgestellt. Die Forschungsergebnisse werden in Bezug auf bestehende Untersuchungen der englischen, deutschen und französischen Literatur in einen internationalen Kontext gestellt.

\section{Terminologische Fragen}

Eine wichtige Aufgabe der Forschung war es, Definitionen der einzelnen Paratexte in der ungarischen Praxis zu klären und dabei vor allem Dedikation von der Vorrede terminologisch abzugrenzen.

Das Unterscheidungsmerkmal zwischen diesen beiden Paratexten des barocken Buches liegt gemäß der literarischen Tradition sowie auch nach Genette in der Person des Empfängers, die den Inhalt, den Aufbau und die Rhetorik des betreffenden Textes beeinflusst. Die Dedikation spricht herkömmlicherweise den Patron (des Autors beziehungsweise des Werkes) an. Mittels einer Dedikation wird, wie Genette definiert, ,ein Werk einer Person, einer wirklichen oder idealen Gruppe oder irgendeiner andersgearteten Entität als Ehrengabe" gewidmet. ${ }^{18}$ Dagegen spielt die Vorrede die Rolle, den ,gnädigen“ Leser anzusprechen, sein Interesse zu wecken und sein Wohlwollen zu erlangen. Die Dedikation wird also durch die Beziehung Autor-Werk-Patron, die Vorrede durch die Beziehung Autor-Werk-Leser in ihren thematischen Schwerpunkten bestimmt. Die Vorrede, als eine Art Bedienungsanweisung des Werkes, ermöglicht zwar seinem Autor die künstlerische beziehungsweise politische Selbstrepräsentation, ordnet sich aber grundsätzlich um das Werk und den Leser. Ihre wichtigsten Funktionen sind die thematische Einordnung und Beschreibung des Werkes sowie die Bestimmung, das Publikum anzusprechen. Genette beschreibt dies wie folgt: „Ich verallgemeinere den gängigen Begriff Vorwort und bezeichne damit alle Arten von auktorialen oder allographen Texten (seien sie einleitend oder ausleitend), die aus einem Diskurs bestehen, der anlässlich des nachgestellten oder vorangestellten Textes

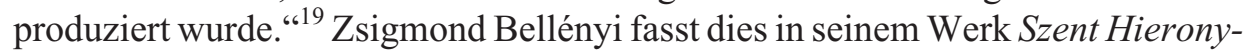
mus Savanarola elmélkedései (Kassa / Kaschau 1618) so zusammen:

Summáját penig mind az egész könyvecskének, rövideden mindenik részének ez elöljáró beszédben rendeltem, hogy az keresztyén olvasót az olvasásra inkább felindíttassam. Melybül megértvén, miről tractáljon, mivel biztasson és mire tanítson, hogy annak utána nagyobb vidámsággal és serinséggel az derék magyarázatnak olvasásához is hozzá nyúlhasson. ${ }^{20}$ 
Laut Ciceros Definition ist das Exordium oder die Einleitung die erste Einheit in der klassischen rhetorischen Aufteilung der Rede - exordium, narratio, argumentatio und peroratio. Ihre wichtigsten Funktionen sind: ,reddere auditores benevolos, attentos, dociles“, 21 also das Wohlwollen des Publikums zu erlangen, seine Aufmerksamkeit zu wecken und die Zuhörer in Bezug auf Rede und Redner wohlwollend zu stimmen. Cicero betont, dass das Exordium den Gegenstand der Rede behandeln soll. Genau wie die Narration selbst, soll es den Gegenstand in den Mittelpunkt setzten, um damit die Narration vorzubereiten. Dementsprechend können Dedikation und Vorrede, wie Zoltán Szabó G. und László Szörényi sowie Csaba Onder andeuten, ${ }^{22}$ als funktionelle Verdoppelung des Exordiums verstanden werden, wobei die Dedikation sich auf die Gefühle, die Vorrede hingegen auf den Verstand auswirkt. Beide Paratexte verwenden den rhetorischen Apparat des Exordiums, allerdings die von Cicero beschriebenen Kriterien der „attentum parare, docilem parare und captatio benevolentiae" sollten in diesem Fall einer Dedikation nicht im Zusammenhang mit dem Publikum, sondern mit den Mäzenen erfüllt werden.

Wie Genettes Definition verdeutlicht, unterscheidet er die Peritexte, also die im Buch vorliegenden Paratexte, nicht nach ihrer Stellung zum (Haupt)Text. Die gängigen Definitionen von Prätexten oder Präliminarien stammen aus dem wissenschaftlichen Diskurs vor Genette und werden - besonders in der ungarischen Fachliteratur - in mehreren Bedeutungen verwendet. Einerseits beziehen sich diese Definitionen auf den ganzen paratextuellen Apparat vor dem Text - inklusive Titelblatt, Verfasserangaben, eventuell sogar Stiche - andererseits werden sie enger, ausschließlich auf einleitende, textuelle Peritexte, also Dedikation und Vorrede begrenzt. Ich folge der Trennung beider Begriffe nach der wichtigsten deutschsprachigen Fachliteratur und verwende den Begriff Prätext ergänzend zu Genettes Paratext-Begriff, also in seiner engeren Bedeutung ausschließlich für die Textgattungen der Dedikation und der Vorrede und den Begriff Präliminarien für die gesamte einleitende Paratextbasis.

\section{Der Korpus und die Mischformen der paratextuellen Gattungen}

Den Korpus der Forschung bilden die mit Dedikationsbrief versehenen, ungarischsprachigen Drucke zwischen 1601 und 1655. Der Forschungskorpus wurde anhand des Verzeichnis[ses] Alter Ungarischer Drucke (RMNy II. und III.) festgelegt, der außerdem als Grundlage für die Klassifizierung, Gruppierung und Einteilung des Korpus und zur Gattungsbestimmung der einzelnen Werke diente. ${ }^{23}$

36 Prozent der in Ungarn herausgegebenen (ungarischen, latein- beziehungsweise fremdsprachigen) Drucke enthalten einen Prätext, das heißt entweder eine Dedikation, oder eine Vorrede, insgesamt also 610 Titel, wovon die Anzahl der 


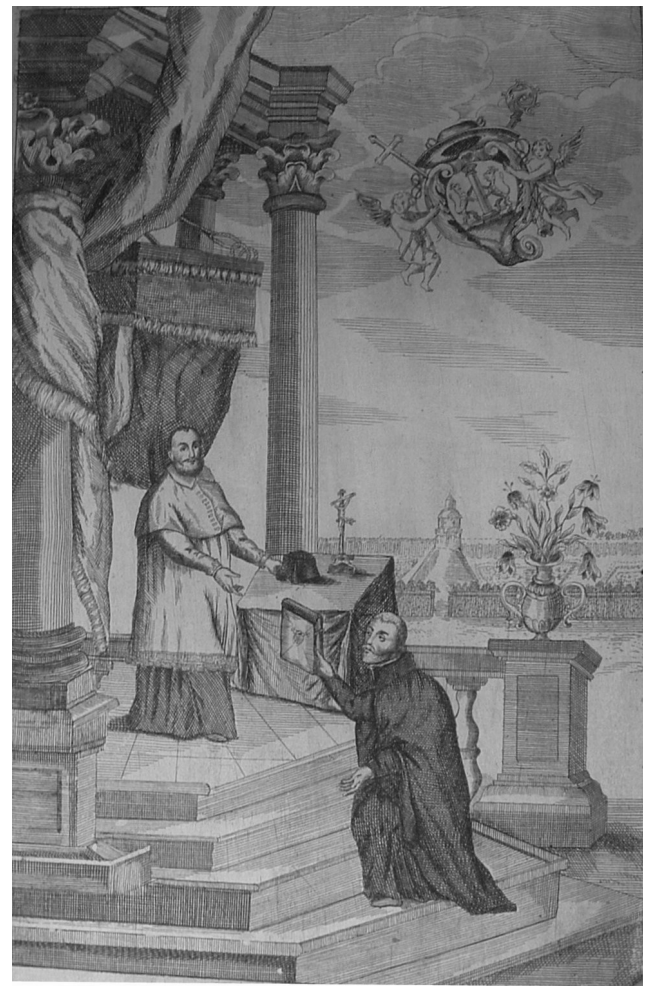

Das einzige bisher bekannte ungarische Dedikationsbild aus dem 17. Jahrhundert in dem Buch von Zacharias Trinkellius: Divinatorium viae et vitae aeternae. Wien, 1663.

(OSZK, RMK III 2201.)

ungarischsprachigen Werke 338 beträgt. Die 610 Prätexte teilen sich in 495 Dedikationen (in Form von Dedikationsbriefen, -bild, -gedichten oder -tafeln) und 152 Vorreden auf. Eine derart starke Dominanz der Dedikationen gegenüber der Vorrede wurde im Zusammenhang der westeuropäischen Literatur nicht beschrieben. Das Überwiegen von Dedikationen im Korpus kann unter anderem mit der formalen und funktionalen Vermischung der Gattungen Dedikation und Vorrede begründet werden. Diese Erscheinung erklärt sich, laut Gertrud Simon, durch den gemeinsamen Ursprung der beiden Gattungen. Die Mischformen können auf die antike Einleitung zurückgeführt werden, in der die Präfationen mit Ansprachen ergänzt wurden und ihren inhaltlichen sowie stilistischen Besonderheiten unterliegen. ${ }^{24}$

In der ungarischen Praxis haben sich zwei solche Formen herausgebildet. Die erste Mischform stellt der Widmungsprolog oder nach István Geleji Katona auch „dedizierende Vorrede“ dar: ${ }^{25}$ hier wird die Vorrede mit einer Adressierung oder eventuell mit Segenswünschen an den Patron ergänzt. ${ }^{26}$ Der Widmungsprolog 
schließt im Allgemeinen die Inhaltsangabe und die Genese des Werkes ein, das also abgesehen von der Adressierung in Form, Inhalt und Stil der Vorrede entspricht. Die gattungstypischen und festen Bestandteile der Dedikation wie Lob des Adressaten oder die Rechtfertigung der Widmungsgeste bleiben zumeist aus. Der Widmungsprolog kommt in der ungarischen Buchproduktion sowohl im 16. als auch im 17. Jahrhundert sehr häufig vor.

Die zweite Mischform der ungarischen Widmungspraxis wird weder in der internationalen, noch in der ungarischen Fachliteratur beschrieben, so dass ein dafür geeigneter Terminus fehlt, obwohl sie rhetorisch und inhaltlich von der Dedikation und der Vorrede ebenso klar zu trennen ist. Diese Form bezeichnet eine Mischung in umgekehrter Richtung, wobei sich die Vorrede an die Leserschaft in die Dedikation einfügt. In diesen Fällen übernimmt also die Dedikation die traditionelle Rolle der Vorrede. Es werden nicht nur der Patron, sondern auch die Leserschaft angesprochen. Weiters tauchen Elemente der Vorrede, wie Werkangaben, Genese, eventuell Quellenangaben usw. auf. Diese Funktionsausweitung der Dedikation ist besonders für jene Werke kennzeichnend, die ausschließlich eine Dedikation und keine Vorrede beinhalten. Bereits in einer der ersten ungarischsprachigen Dedikationen, in Szent Pál levelek von Benedek Komjáthi kommt diese Mischgattung vor: die an die ,gnädige Gräfin, Fräulein Katalin, Gattin des ehemaligen gnädigen Gábriel Perény“ adressierte Dedikation wendet sich im letzten Absatz ohne weitere Anrede an die „Leser von Paulus' Briefen“ und stellt im Sinne einer Vorrede die Prinzipien der Übersetzung dar. ${ }^{27}$

Neben der formalen und funktionalen Mischung der paratextuellen Gattungen lässt sich in der ungarischen Literatur des 16. und 17. Jahrhunderts eine allgemeine terminologische Unsicherheit beobachten. Während deutsch- oder englischsprachige Prätexte mit der antiken Terminologie (Dedikationsbrief oder Widmungsbrief vs. Vorrede; dedication vs. preface) konsequent umgehen, sind in der ungarischen Literatur Präliminarien keine Seltenheiten, in denen der Autor den Prätext, der nach formalen und inhaltlichen Kriterien als Dedikation verstanden werden kann, im Titel als Vorrede bezeichnet, oder einen im Titel Dedikation genannten Text später als Vorrede zitiert. Ein Beispiel zeigt die Dedikation des Werkes Mennyei lámpás (Göttliche Laterne) von János Bökényi Fülep an die Adelsherren des Komitats Ugocsa:

Tekéntetes, nagyságos, nemes, nemzetes és becsületes Uraim, hogy ez kis könyvecskét nem csak magyarul szóllani tanétottam, hanem egyszersmind az Nagyságtok és Kegyelmetek méltóságos neve alatt is világra bocsátani nem átallottam, [...] mindenik okoknak előszámlálásának befoglalására ez könyvecske az ő kicsinsége miatt úgy ítélem elégtelen volna, mert így ez elöljáró beszéd magánál netalám nagyobbra terjedni fogna, hanem a többit elhallgatván légyen elég ok az én Nagyságtokhoz s Kegyelmetekhez és Hazánkhoz való buzgó indulatbéli szeretetemnek mivolta. ${ }^{28}$ 
Das Phänomen der terminologischen Unsicherheit lässt sich nur bis ins 18 . Jahrhundert nachverfolgen; die formalen Mischformen existieren demgegenüber in der ungarischen Literatur bis zur formalen und funktionalen Umwandlung der Dedikationsgattung.

\section{Rhetorik}

Die Rhetorik der Dedikation wird grundsätzlich von Ziel und Funktion der Gattung, vor allem vom Ansprechen des Patrons, der Repräsentation der Unterstützung und dem Ausdruck der Dankbarkeit bestimmt. Die Form der Dedikation ist im Allgemeinen der Brief, wie bereits erwähnt, nur in einzelnen Fällen - etwa als Ergänzung zum Dedikationsbrief - tauchen Widmungstafeln, -gedichte oder bilder auf.

Obwohl die den mittelalterlichen Schemata folgende Dedikationspraxis in Ungarn etwa hundert-hundertfünfzig Jahre länger zu beobachten ist, und die Kritik der Dedikationspraxis viel später einsetzt, folgt die Rhetorik der ungarischen Dedikationen des 17. Jahrhunderts den zeitgenössischen europäischen Mustern.

Für den Aufbau der Widmungsepistel gelten traditionell die rhetorischen Regeln der Briefgattung. Orientierung bot dazu die Briefstellerkunst, die lateinischen oder in manchen Ländern auch in der Nationalsprache verfassten Briefrhetoriken. Die Dedikationen werden als die imposanteste Form der Briefgattung in vielen Briefstellerkunstbüchern, so in den Werken von Bohse, ${ }^{29}$ Morhof,${ }^{30}$ Neukirch, ${ }^{31}$ Harsdörffer, ${ }^{32}$ Stieler ${ }^{33}$ oder Stockhausen behandelt. ${ }^{34}$ Diese stellen neben Beispieltexten auch Anleitungen zur Dedikation, zu Regeln und Aufbau und das angemessene Lob dar.

Für den ungarischen Forschungskorpus, ähnlich wie für den deutschen, ist größtenteils der aus dem Mittelalter tradierte, rhetorische Aufbau prägend: salutatio (Gruß), captatio benevolentiae (Erlangen des Wohlwollens), narratio (Narration), petitio (Bitte), conclusio (Schluss). ${ }^{35}$ Die Tabelle (S. 52) zeigt anhand des Forschungskorpus das Aufbauschema der ungarischen Dedikationen.

Im Allgemeinen kann gesagt werden, dass jede Dedikationsepistel mit einer Anrede anfängt (salutatio). Eine generelle Regel der Anrede ist die Auflistung der gesamten Titulatur und Rangangabe des Adressaten. Oft kommt es vor, dass die salutatio eine eigene Seite bekommt, welche sich von der Dedikation auch typographisch absondert und eine so genannte Widmungstafel bildet. Der Name des Adressaten (im Fall einer weiblichen Patronin auch der Name des Mannes) ist sowohl auf einer Widmungstafel als auch in einem Dedikationsbrief versal gedruckt. Typographische Besonderheiten der Widmungstafel sind des weiteren die immer kleiner werdende Schrift und der mittig gestellte Text. 


\begin{tabular}{|c|c|c|c|c|c|c|}
\hline SALUTATIO & $\begin{array}{c}\text { CAPTATIO } \\
\text { BENEVO- } \\
\text { LENTIAE }\end{array}$ & (Eingang) & $\begin{array}{l}\text { NARRATIO } \\
\text { (Vortrag) }\end{array}$ & $\begin{array}{c}\text { (Bestäti- } \\
\text { gung) }\end{array}$ & $\begin{array}{c}\text { PETITIO } \\
\text { (Schluss) }\end{array}$ & CONCLUSIO \\
\hline \multirow{3}{*}{$\begin{array}{l}\text { Einfache } \\
\text { Anrede }\end{array}$} & $\begin{array}{l}\text { Erneute } \\
\text { Anrede }\end{array}$ & $\begin{array}{l}\text { Themenangabe } \\
\text { und thema- } \\
\text { tische } \\
\text { Abhandlung }\end{array}$ & $\begin{array}{l}\text { Der illokutive } \\
\text { Akt der } \\
\text { Darbringung } \\
\text { des Buches }\end{array}$ & \multirow{4}{*}{$\begin{array}{c}\text { Lobtopoi } \\
\text { über den } \\
\text { Mäzen }\end{array}$} & \begin{tabular}{|} 
Bitte \\
bezüglich \\
des \\
Mäzens
\end{tabular} & \multirow{4}{*}{$\begin{array}{l}\text { Glück- } \\
\text { wünsche } \\
\text { und } \\
\text { Schluss- } \\
\text { formeln }\end{array}$} \\
\hline & $\begin{array}{c}\text { Der } \\
\text { illokutive } \\
\text { Akt der } \\
\text { Darbringung } \\
\text { des Buches }\end{array}$ & \multirow{2}{*}{$\begin{array}{l}\text { Entstehungs- } \\
\text { geschichte und } \\
\text { Rechtfertigung } \\
\text { des Werkes }\end{array}$} & $\begin{array}{l}\text { Begründung der } \\
\text { Adressierung } \\
\text { der Dedikation }\end{array}$ & & $\begin{array}{c}\text { Bitte } \\
\text { bezüglich } \\
\text { des } \\
\text { Werkes }\end{array}$ & \\
\hline & - & & $\begin{array}{l}\text { Bescheiden } \\
\text { heits-topoi }\end{array}$ & & $\begin{array}{c}\text { Bitte } \\
\text { bezüglich } \\
\text { des } \\
\text { Autors }\end{array}$ & \\
\hline $\begin{array}{c}\text { Einfache } \\
\text { Anrede }\end{array}$ & $\begin{array}{l}\text { und } \\
\text { Segens- } \\
\text { wünsche }\end{array}$ & $\begin{array}{l}\text { Begründung der } \\
\text { Adressierung } \\
\text { der Dedikation }\end{array}$ & $\begin{array}{l}\text { Weitere } \\
\text { rhetorische und } \\
\text { inhaltliche } \\
\text { Elemente }\end{array}$ & & - & \\
\hline
\end{tabular}

Die einführende Form der Widmungsepisteln, die salutatio, wird meistens mit Glück- beziehungsweise Segenswünschen und dem illokutiven Akt der Darbringung des Buches ergänzt (captatio benevolentiae).

Der Hauptteil der Dedikation (narratio und petitio) wird den Dedikationsregeln von Bohses Briefstellerkunst entsprechend meistens in vier Teile gegliedert: Eingang, Vortrag, Bestätigung und Schluss. ${ }^{36}$ Diese Aufteilung kann man auch nach dem klassischen Briefschema interpretieren: zur Narration gehören demnach Eingang, Vortrag und Bestätigung, während der Schluss der Petitio entspricht. Diese Grundeinheiten der Dedikation sind inhaltlich um das Werk und den Mäzen geordnet. Dementsprechend besteht der Eingang entweder aus der Themenangabe einer inhaltlichen Zusammenfassung, oder aus den Lobtopoi über den Patron. Die Ausführung und Länge der Abhandlung über das Werk variiert je nachdem, ob im Buch ein Vorwort vorhanden ist. In ungarischen Dedikationen kommt es häufig vor, dass die Themenangabe einer ausführlichen Abhandlung zumeist über theologische Fragen folgt, die im Vortrag um Angaben zur Quellen, zur Stil oder manchmal zur Gattung sowie bei Übersetzungen um die Art und Weise der Translation ergänzt wird. Dies ist besonders für Werke ohne Vorwort 
typisch; in diesen Mischformen übernimmt die Dedikation, mit dem Ansprechen der Leserschaft und dem Erlangen des Wohlwollens, die Rolle eines Vorwortes. Falls im Buch auch ein Vorwort vorhanden ist, werden diese Angaben in der Regel dort angeführt.

Der Eingang der Narration dient eigentlich dazu, das Rühmen des Patrons vorzubereiten - so drehen sich Vortrag und Bestätigung fast ausschließlich um den Mäzen. Die festen Bestandteile der Narration bilden folglich die Darbringung des Werkes (sowie gegebenenfalls die Wiederholung derselben), die Begründung der Adressierung und stehen in Zusammenhang mit diesem Bescheidenheitstopos oder -topoi. Die Lobtopoi über den Mäzen, seine Person, seine Taten und seine Güte werden in ungarischen Widmungsepisteln überwiegend im letzten Teil der Narration, in der Bestätigung aufgezählt.

Auf die Narration folgt die Bitte, also petitio, welche sich entweder auf das Werk oder den Autor bezieht und von der Patronage bestimmt wird. Beispiele dafür wären die Bitte, dass der Patron das angebotene Werk annimmt oder die Bitte um weitere Unterstützung. Darüber hinaus kann sich die petitio auf den Patron beziehen, das heißt, der Autor bittet um das Wohl seines Patrons.

Aus der grundlegenden Funktion der Dedikation, der Repräsentation der Patronage, erklärt sich, dass das wichtigste und häufigste rhetorische Mittel der Lobtopos darstellt. Die Lobtopoi werden in der antiken Redeart durch den genus demonstrativum konstituiert. Das Objekt der Verehrung ist in diesem Fall selbstverständlich der Mensch (a persona), der Patron. Nach dem hellenistischen Zeitalter waren für Lobtopoi über Herrscher oder hohe Persönlichkeiten feste Schemata im Gebrauch. Das wichtigste Schema ist nach Curtius die aus drei Elementen bestehende Konstellation von Schönheit - hoher Abstammung - Tugendhaftigkeit, deren Variante ist die Viererkonstellation von Schönheit - hoher Abstammung Macht - Reichtum. ${ }^{37}$ Die Quellen dieser Formeln sind vorwiegend in antiken Texten zu finden, die durch biblische Analogien ergänzt werden.

Diese Formeln werden in der ungarischen Dedikationsgattung stark modifiziert: die Topoi über die Person des Patrons werden gar nicht oder nur oberflächig ausgeführt, wohingegen die Wohltaten des Mäzens gegenüber dem Autor und seine allgemeine Patronentätigkeit detailliert dargelegt werden.

Die Lobtopoi in ungarischen Dedikationen können in drei Gruppen eingeteilt werden: persönliche und religiöse Topoi sowie das Lob der Patronage. Zu den persönlichen Lobtopoi gehören nach der Einordnung von Quintilianus das Lob der hohen Abstammung (genus und natio), der Tugendhaftigkeit und Waffentüchtigkeit (fortitudo oder virtus), der guten Bildung und der Aufgeschlossenheit für Wissenschaft, Kunst und Literatur (educatio et disciplina) und der Schönheit (forma). ${ }^{38}$

Nach Leiner ist das Lob der hohen Abstammung der wichtigste Topos der Dedikationen. ${ }^{39}$ Sein Gebrauch war in der mittelalterlichen Literatur in ganz Europa 
weit verbreitet. In ungarischen Dedikationen des 17. Jahrhunderts ist es auch zu finden, allerdings begnügen sich die Autoren damit, die hohe Abstammung in der Anrede oder in kürzeren Wendungen hervorzuheben wie: „Nemes vér pozsdul testében“, „gerjedez nemesi vér benne“, 40 „Felséged nemzetségének fejedelmi híre“41 oder „,nagy királyi dicsőségnek fényességével felséged nemzetsége részesíttetik“. ${ }^{42}$

Wie bereits Cicero betont, geht die Tugend der Waffentüchtigkeit und Heldenmut der Abstammung vor: ,virtute, non genere commendari““ ${ }^{43}$ Die Verbreitung des Topos der Tugendhaftigkeit knüpft an Homers Odyssee und wird bereits bei Vergil mit dem Topos der Pietas ergänzt. Aeneas wird dementsprechend wie folgt beschrieben: „,...pietate insignis et armis“ “ ${ }^{44}$ In der ungarischen Dedikation wird fast ausschließlich diese Vergilische Form, der Topos fortitudo et pietas benutzt. Ein Beispiel zeigt die Dedikation des Werkes Az pápisták között és mi közöttünk vetélkedésre vettetett három fö articulusokról von János Kecskeméti C. an Ferenc Darholcz:

\begin{abstract}
Hallottam és értettem, sőt minekutána kegyelmednek ismeretségében jutottam, láttam az kegyelmed istenfélő keresztyéni voltát, és az igaz vallásban való oly fondaltatását, hogy efféle dolgokban senkitől semmit nem röttög kegyelmed, sőt, ha kívántatnék, hiti s vallása mellett halált is szenvedni kész volna kegyelmed. ${ }^{45}$
\end{abstract}

Die Topoi der educatio et disciplina kommen in dieser Gattung entsprechend häufig vor. In ungarischen Dedikationen existieren zwei Formen: eine allgemeinere und eine, die auf die Patronage Bezug nimmt. In der zweiten wird also die Aufgeschlossenheit für Wissenschaft, Kunst und Literatur bezüglich der Patronentätigkeit gelobt.

In der ersten Form werden die Bildung und das Wissen des Patrons hervorgehoben. Diese Form kommt besonders in Zusammenhang mit Patroninnen zum Ausdruck. So widmet János Samarjai sein Werk Magyar harmónia Orsolya Echi:

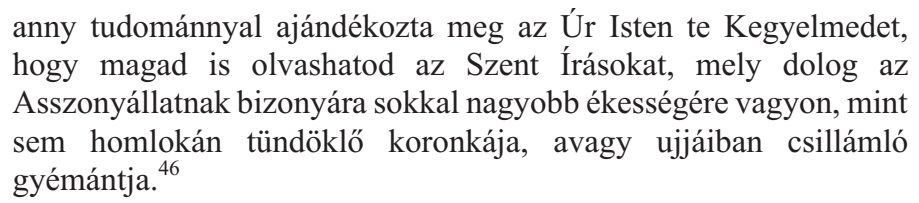

Das Lob über den Alphabetismus im Hauptwerk von Samarjai, der Frieden zwischen der lutherischen und kalvinistischen Kirche anstrebte, ist nicht überraschend, da die Lesefähigkeit der Frau gerade eben mit der Reformation eine besondere ideologische Bedeutung bekommen hat. Ihre Wichtigkeit wurde selbst von Luther betont, der öfter hervorhob, dass die Lesefähigkeit der Frau die Lektüre der Bibel und weiterer erbaulicher Texte ermöglicht. ${ }^{47}$ Dieses Lob bekommt im 
Text von Samarjai dadurch eine besondere Bedeutung, dass es gegenüber der Schönheit betont wird.

Der Topos der Schönheit ist das wichtigste und älteste Lob an Frauen. Laut Leiner kommt er in der französischen Literatur sehr häufig vor. In der ungarischen Literaturgeschichte der ersten Hälfte des 17. Jahrhunderts findet sich trotz der hohen Anzahl der weiblichen Patronage nur ein einziges Beispiel dafür in der Dedikation von Mátyás Hajnals Szíves könyvecske:

\begin{abstract}
Micsoda több jót cselekedett mindezeknél még az Istennek benned és veled munkálkodó malasztja, megmutatja ezt az kilencedik szívnek képe, kiben az mennyei Vőlegény virágokat hinteget; mely virágok nem egyebek, hanem az te jóságos cselekedetidnek sok és szép tökéletességi, melyekkel az Szentlélek felékesétette az te lelkedet, tebeléd helyheztette az szeretetnek nap után forgó sárga virágját; beléd ültette az ájtatosságnak izzadó balsemumját, beléd az tisztaságnak fejér liliomját; beléd az szemérmetességnek piros rózsáját, beléd az mértékletes szólásnak gyöngyvirágját, beléd az kegyességnek fodormentáját, az alázatosságnak izsópját, erősségnek szegfüjét, türésnek rozmarinját, állhatatosságnak puszpángját, több tökéletes szépségnek gyönyörüséges virágait. ${ }^{48}$
\end{abstract}

Das Lob der Schönheit vermischt sich hier mit einem weiteren wichtigen Lobtopos ungarischer Dedikationen: mit dem Topos pietas. Diese stellt die Frömmigkeit, die erbauliche Lebensart sowie die Tätigkeit und den Willen des Patrons dar, die Kirche zu beschützen und zu unterstützen. In ungarischen Paratexten hat das Lob der Frömmigkeit drei Formen, die allerdings stark zusammenhängen und sich oft vermischen: in der ersten wird das Beschützen der Kirche (das oft mit der Tugendhaftigkeit zusammengeführt wird - fortitudo et pietas), in der zweiten die Unterstützung der Entwicklung von Religion und Kirche, und in der dritten die Liebe zu Gott und dem Glauben sowie das erbauliche Leben gelobt.

Letzteres, das Lob der Frömmigkeit und des pietistischen Lebens, wird fast ausschließlich im Zusammenhang mit Frauen erwähnt. So werden unter anderem Krisztina Nyáry von János Mihálykó, ${ }^{49}$ Homonnai Mária von István Deselvics ${ }^{50}$ und Márton Madarász, ${ }^{51}$ Wardai Kata von János Kecskeméti C., ${ }^{52}$ Illyésházi Kata von István Bethlen, ${ }^{53}$ Orsolya Echi von János Samarjai ${ }^{54}$ und Zsuzsanna Lorántffy von István Geleji Katona gelobt:

Boldognak méltán mondhatom Nagyságodat, kegyelmes Asszonyom, kit Isten ilyen nagy lelkủ és elméjü, méltóságos férjjel, ilyen kegyes erkölcsű fiakkal megáldott s magában is ennyi sok üdvösséges lelki ajándékokat, úgy mint a vallásban való tudósságot, a hitbéli állhatatosságot, az ő szent igéjéhez való buzgó szeretetet, a könyörgésben való forró ájtatosságot és az ő dicsőségének s igaz tiszteletinek elégyámolíttatására való szorgalmatos ügyekezetet öntött, me- 
lyekben mind fiainak s mind menyeinek, mind éltében s mind holta után jó oktató és indító példájok lehet. ${ }^{55}$

Wie im Fall des Lobes der weiblichen Lesefähigkeit, hängt der häufige Gebrauch dieses Lobes mit der ungarischen Verbreitung der Erbauungsliteratur zusammen. Diese war die erste und für lange Zeit einzige Literatur, die bewusst Frauen und Mädchen als Lesepublikum angezogen hat. ${ }^{56}$ Dieses Phänomen setzte mit dem Auftritt des Protestantismus und dessen Reformbewegungen - dem Pietismus in Deutschland oder dem Puritanismus in England - ein: das Subjekt und die Innerlichkeit der Gläubigen wurden betont wie auch die persönliche und innere Frömmigkeit des Einzelnen. Dem Protestantismus als sozialreligiöse Reformbewegung ging es um die mystische Idee einer inneren religiösen Bildung und Formung und um das Problem der individuellen Glaubensversicherung und -bewährung. Dabei richtete sich der Ruf nach Buße und Bekehrung nicht an Mann oder Frau, sondern an alle wahren Christen. ${ }^{57}$ Diese Gattung (Erbauungsliteratur) erfüllte im 17. Jahrhundert die Rolle der schönen Literatur: die intensive und regelmäßige Lektüre religiöser Texte gehörte wesentlich zur täglichen erbaulichen Praxis der Frauen. Die hohe Anzahl der Adressatinnen, die in den Vorwörtern und Dedikationen der Erbauungsliteratur angesprochen wurden, zeugt also von einer deutlichen Präsenz der weiblichen Leserschicht in Ungarn. ${ }^{58}$

Die häufigsten und detailliertesten rhetorischen Mittel der Dedikationen stellen die Lobtopoi über die Patronage dar. Sie betreffen einerseits die Unterstützung und den Schutz des Werkes und würdigen andererseits in allgemeiner Form die Großzügigkeit und Weitherzigkeit des Patrons. Im Falle des untersuchten Korpus finden sich häufig ergänzende persönliche und religiöse Lobtopoi, die die Patronentätigkeit verstärkt rühmen.

Die Wirkung des Lobes wird weiterhin durch einen allgemeinen und sehr verbreiteten Topos verstärkt, der versichert, dass der Mäzen des Autors noch viel tugendhafter sei, die Eigenschaften allerdings aus Platzgründen nicht aufgezählt werden können.

Ungarischsprachige Dedikationen haben zwei weitere ständige rhetorische Bestandteile: die Bescheidenheitstopoi und die Exordiumtopoi. Die Bescheidenheitstopoi können, wie viele andere feste Bestandteile des Prologs und der Dedikationen, aus der antiken Literatur hergeleitet werden. Nach Quintilianus soll die Bescheidenheit die Gunst des Lesers und sein freundliches Urteil bewirken: „ite quaedam in his quoeque commendatio tacita, si nos infirmos, imparatos, impares agentium contra ingeniis dixerimus, qualia sunt pleraque Messalae prooemia, est enim naturalis favor pro laborantibus [... " ${ }^{59}$ Wie Simon betont, gewinnt die Autorenbescheidenheit im Mittelalter durch die christlichen Anschauungen vom Werte der Demut eine größere Bedeutung. Unabhängig von seiner Form, die entweder aus einer festen Konstruktion oder einer längeren Ausführung besteht, be- 
inhaltet der Bescheidenheitstopos die Degradierung der Talente und Verdienste des Autors selbst. Dementsprechend bezieht er sich entweder auf den Autor oder - in Zusammenhang mit diesem - auf das Werk.

Ehrenzeller unterscheidet anhand der deutschen Literatur des 17. und 18. Jahrhunderts (vor allem bei Grimmelshausen und Jean Paul) zwei Formen des Bescheidenheitstopos: die ästhetische und die moralische Rechtfertigung. Die ästhetische Rechtfertigung erläutert laut Ehrenzeller die Gattung und Sprache des Werkes und arbeitet vor allem mit kunsttheoretischen Gesichtspunkten. Die moralische Rechtfertigung hingegen beschäftigt sich vor allem mit Vorwürfen im Zusammenhang mit dem Autor sowie dem Thema und dem Inhalt des Werkes (Zeitverschwendung, Unsittlichkeit, Unwahrheit usw.). ${ }^{60}$ Nach Ehrenzeller zählen beide Formen zum Vorwort, allerdings zeugen die ungarischen Dedikationen von einer anderen Praxis. Die ästhetische Rechtfertigung wird - falls vorhanden - tatsächlich im Vorwort besprochen und oft mit der Rechtfertigung über die ungarische Sprache des Werkes sowie durch den Topos des sprachlichen und kulturellen Rückstands des Landes ergänzt. Die moralische Rechtfertigung ist hingegen wegen der formalen und funktionalen Mischung der paratextuellen Gattungen in der ungarischen Literatur fast ausschließlich in Dedikationen zu finden.

Der Exordiumtopos ist mit der von Hans Ehrenzeller definierten moralischen Rechtfertigung, das heißt mit dem auf das Werk bezogenen Bescheidenheitstopos verwandt. Im Exordiumtopos reflektiert der Autor die Gründe für das Schreiben und die Herausgabe des Werkes. Diese Gründe beziehen sich in ungarischen Dedikationen auf den Patron, das Werk oder dessen Thema und können auch von außen herrühren, wie beispielsweise aus der Heimatsliebe oder der religiösen Überzeugung. Diese Gründe treten oft kombiniert auf.

\section{Mäzenatentum}

Der Aufbau und die rhetorische Konstruktion der Dedikation dienen dazu, die Patronage zu illustrieren und die Beziehung des Autors zu seinem Mäzen zu stärken. Das gilt fast für jede Dedikation: unter den 279 untersuchten ungarischsprachigen Dedikationen sind nur 52 (18 Prozent) zu finden, in denen die Autoren die Patronage nicht ansprechen. Die Tendenz ist absteigend, zwischen 1601 und 1635 bleiben etwa 36 Drucke ohne Erläuterung der Patronage, und zwischen 1636 und 1655 sind nur 16 dieser Bücher zu finden. Der fehlende Hinweis auf die Patronage bedeutet allerdings nicht, dass keine Unterstützung geboten wurde, im Gegenteil - irgendeine Art von Beihilfe bestand vermutlich in den meisten Fällen.

Im gesamten Forschungskorpus befinden sich nur 22 Drucke in denen zwischen Autor und Adressat der Dedikation die traditionelle Künstler-Mäzen-Beziehung mit Sicherheit ausgeschlossen werden kann. Diese Dedikationen spre- 
chen Familienangehörige, ${ }^{61}$ allgemeine Adressaten wie das Volk der jeweiligen Kirche, ${ }^{62}$ den ungarischen Adel, ${ }^{63}$ übernatürliche Personen wie Gott oder Heilige $^{64}$ sowie in den Kampfschriften von Pázmány mitunter den Gegner oder dessen Patron an. ${ }^{65}$

Hinter der Adressierung der Dedikationen steht also meistens eine bestehende Patronage. Die Formen der literarischen Patronage im 17. Jahrhundert in Ungarn korrellieren mit den drei Kategorien des Kunstmäzenatentums im Renaissance-Italien, die von Peter Burke beschrieben wurden. Zur ersten Kategorie zählt die höfische Patronage, die gegeben ist, sofern der Dichter oder Schriftsteller im ständigen Dienst an einem Hof steht. Die zweite Kategorie ist die Patronage einzelner Werke, wobei die Unterstützung nicht die Person des Autors, sondern seinen Werk betrifft. Drittens spricht Burke von einem Mäzenatentum, das auf dem Markt basiert, wobei die Drucke entsprechend der Nachfrage des Buchmarktes in der Hoffnung auf finanziellen Erfolg publiziert werden. Die dritte Form ist in Ungarn im 17. Jahrhundert noch ziemlich selten, sie kommt fast ausschließlich bei Kalendern vor. Bei anderen Werken, die auf eigene Kosten des Autors herausgegeben werden, ist die Motivation der Autoren meist nicht der finanzielle Gewinn, sondern die eigene religiöse, erbauliche Überzeugung.

$\mathrm{Zu}$ der Kategorisierung der Patrone wird wiederum auf Burkes Werk zurückgegriffen: das weltliche-kirchliche Mäzenatentum wurde dementsprechend weiter verfeinert und auf einzelne und institutionelle Mäzenen aufgeteilt. Von den eruierten Patronenkreisen der ungarischen Literatur kann man von einem auffälligen Übergewicht der weltlichen Patronage ausgehen. Dabei spielt das institutionelle Mäzenatentum bei der weltlichen, ebenso wie bei der kirchlichen Patronage eine marginale Rolle. Folgende Abbildung (S. 59) zeigt die Übersicht der ungarischen Mäzene der Zeit.

Die wichtigste und größte Gruppe bilden Fürsten und Hochadelige. Das ist jene Gruppe, die in der höfischen Patronage die am Hofe arbeitenden Künstler unterstützte. Das Übergewicht der weltlichen Patronage ist verständlich, überraschend ist nur ihr Ausmaß. Im gesamten Forschungskorpus von 279 ungarischsprachigen Büchern sind nur 22 zu finden, deren Druck von einer kirchlichen Person oder Gruppe unterstützt wurde. Der niedrige, unter 10 Prozent liegende Anteil der Kirche am literarischen Mäzenatentum entspricht genau dem Verhältnis der Literaturen anderer Länder. Leiner berichtet von etwas mehr als 7 Prozent in der französischen Literatur, Schottenloher vermutet eine ähnliche Rate von weniger als 10 Prozent für Deutschland. ${ }^{66}$

Die Zahl der unterstützten Werke pro Patron (oder Patronengruppe) fällt natürlich umso größer aus, je höher die gesellschaftliche Stellung des Patrons ist. In der Gruppe der Fürsten kann man einen Durchschnitt von etwa 3,4 Drucken pro Person feststellen, im Fall der Hochadeligen 2,2 und in der Gruppe des Mittel- und Kleinadels sowie der Bürger liegt der Wert bei nur noch 1,1 Drucken pro Person. 


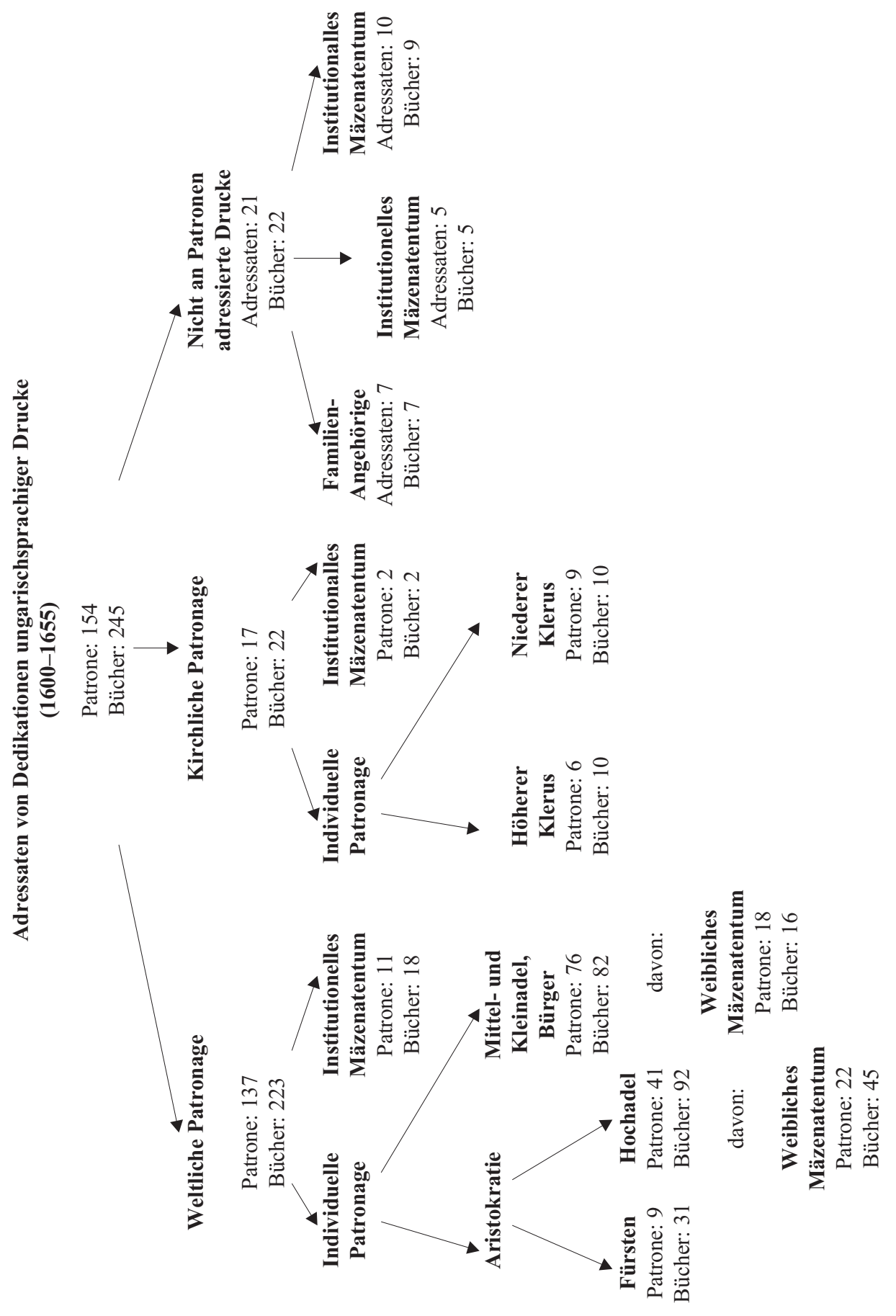


Diese Verhältnisse sind auch für die kirchlichen Patronenkreise kennzeichnend, wobei der höhere Klerus durchschnittlich 1,5 Drucke und der niedere Klerus 1,1 Drucke förderte.

Im Patronenkreis der ungarischen Literatur zeichnet sich des Weiteren ein markantes weibliches Mäzenatentum ab. 61 Drucke, also etwa 22 Prozent der Gesamtproduktion ungarischsprachiger Werke, wurden von Frauen protegiert. In der Gruppe des Mittel- und Kleinadels liegt die Anzahl der Patroninnen bei 31 Prozent, unter den Hochadeligen ist sogar mehr als die Hälfte der Patrone eine Frau (53 Prozent). Obwohl in den meisten Fällen, besonders beim kleinen und mittleren Adel und bei Bürgerinnen davon auszugehen ist, dass die eigentliche Gönnerschaft vom jeweiligen Ehemann stammt, ist die Zahl der 40 Patroninnen überragend, was, wie bereits festgestellt wurde, auf eine starke Präsens des weiblichen Lesepublikums hindeutet, das vor allem Erbauungsliteratur konsumierte. So ist kaum verwunderlich, dass Dedikationen, die Frauen ansprechen, meistens in erbaulichen Büchern auftauchen.

Laut der Widmungsbriefe hängen die Gründe der Autoren für die Auswahl ihrer Patrone meistens auch mit der Art der Patronage zusammen. Die Ausdrücke der Dankbarkeit für die Unterstützung sowie die Bitte um Schutz für das Werk und den Autor selbst sind in fast jedem Dedikationsbrief zu finden. Weitere Gründe, wie die Ähnlichkeit zwischen dem Patron und dem Helden des Werkes oder die geographische Nähe zwischen dem Druckort des Werkes oder dem Dienstort des Autors zum Sitz des Patrons, kommen im Vergleich mit Dankbarkeitsgründen selten vor. Der zweitwichtigste Grund zur Auswahl ist der Wille zur Verbreitung des Ruhms eines Patrons, welcher neben der Illustration der Patronage auch auf eine wichtige Motivation der Mäzene hindeutet.

Prestige als Beweggrund zur Kunstförderung betont auch Burke für das Italien der Renaissance. Dieser Verweis auf den Ruhm des Gönners widerspricht dem wichtigen Kriterium der Bescheidenheit. Trotzdem wird er von vielen Autoren betont. Die Patronage spielte demnach vermutlich eine viel wichtigere Rolle bei der Gönnerschaft als aus den Dedikationen zu schließen wäre. Als deutlich wichtigerer Beweggrund des Gönners kann die religiöse Andacht erwähnt werden. Einerseits wird dies aus dem Gattungsprofil der ungarischsprachigen Literatur klar, andererseits zeugen die häufigsten Lobtopoi der Widmungen, wie das Lob der Frömmigkeit, ebenso davon. Der dritte Motivationsgrund in Burkes Theorie, der des künstlerischen Vergnügens, wird in der ungarischsprachigen Literatur ebenfalls ausschließlich in Zusammenhang mit der Frömmigkeit erwähnt. ${ }^{67}$

Ergänzend zu Burkes These kann in der ungarischen Literatur ein vierter Grund zur Literaturpatronage festgestellt werden, und zwar die Absicht, die Zahl der ungarischsprachigen Werke zu vermehren. Der Mangel an ungarischen Büchern, der in Exordiumtopoi der Dedikationen häufig beklagt wird, inspiriert so- 
mit nicht nur die Autoren dazu, ungarische Texte zu verfassen beziehungsweise fremdsprachige Literatur zu übersetzen, sondern motiviert auch Patrone dies zu unterstützen oder sogar selbst zu initiieren.

\section{Historischer Ausblick}

Die Tradition der Widmungen an Mäzene stammt aus der Antike und beginnt etwa im 1. Jahrhundert vor Christus. Davor ist es üblich, dass die Autoren ihre Werke einem Freund oder einem anderen Schriftsteller dedizieren und ihn dazu auffordern, das Werk kritisch zu lesen. Laut der Fachliteratur der europäischen Widmungsgeschichte verliert die Dedikation bis zum Ausgang des 17. Jahrhunderts nicht an Bedeutung, allerdings wird ab Mitte des 17. Jahrhunderts der Gebrauch von Dedikationen seltener, und im Verlauf des 18. Jahrhunderts verliert die rhetorische Kunst des Dedikationsbriefes endgültig ihre Funktion. Fortan werden kurze Widmungsformeln oder einfache Namensnennungen bevorzugt, die auf eine freundschaftliche oder familiäre Beziehung hindeuten.

Für diese Entwicklung nennt die Fachliteratur drei Gründe: der wichtigste liegt in der Entstehung eines breiten Lesepublikums und seinem Anspruch auf nationalsprachige Literatur. Infolge der verstärkten Rolle des Marktes in den Künsten kann sich der Autor von seinem Patron immer weiter ablösen. Die so entstehende künstlerische Emanzipation wirkt sich auf die Dedikationen aus und lässt die Widmung an den Patron um eine finanzielle Unterstützung zurücktreten. ${ }^{68}$

Darüber hinaus spielt die starke Kritik an der antiken rhetorischen Tradition auch eine bedeutende Rolle für den Bedeutungsverlust von Dedikationen. Die Kritik der formalen Gebundenheit verursachte Monotonie, die bereits mit Platon anfängt und bis zur grundsätzlichen Ablehnung der Rhetorik von Kant ständig präsent bleibt. ${ }^{69}$

Nicht zuletzt ist der dritte Grund nach Leiner, Schramm und Richardson die zeitgenössische Aburteilung über die Dedikationspraxis als Bettelei um das Honorar. ${ }^{70}$ In Italien tritt die Kritik der Gattung bereits im 16. Jahrhundert auf. Giovanni Fratta widmet im Jahr 1590 ein ganzes Werk Della dedicatione de 'Libri con la correzion dell 'Abuso in questa materia introdotto ${ }^{71} \mathrm{dem}$ Thema, worin er betont, dass die meisten Autoren die Widmungen dazu benutzen, finanzielle Unterstützung zu bekommen. ${ }^{72}$

Si come i volumi de' buoni Autori, ne' miglior tempi, apportarono gloriosa reputazione à que' personaggi, à qui erano inviati, cosi ne' presenti giorni, vengono ad essere d'incerto honore, à chiunque si dedicano, per l'obliqua disposizione de molti scrittori. ${ }^{73}$ 
In der deutschen Literatur wird diese Kritik sogar in der Briefstellerkunst, dem rhetorischen Handbuch des Briefes (unter anderem in Widmungsbriefen) betont, wie Stieler in seinem Werk Teutsche Sekretariatkunst schreibt:

\begin{abstract}
Heute zu Tage sind dergleichen Geschenke gemeiniglich prächtige Betteleyen, und ist deren Zweck mehrenteils auf Erschnappung eines Gegengeschenks, das noch eins oder zehenfach mehr wert sei als das Buch war gerichtet. Fürsten und Herren aber riechen diese Braten, darum weisen sie solche Bettler durch Ihrige meisterlich ab, oder beantworten ihre Dedicationsbriefe mit Stillschweigen. ${ }^{74}$
\end{abstract}

Die Kritik an der starren Rhetorik und der Dedikationspraxis erscheint in der ungarischen Literatur ebenfalls im 17. Jahrhundert. Eine der ersten kritischen Anmerkungen stammt von Pál Medgyesi, der selbst in höfischer Patronage, der engsten Patronenbeziehung stand. Medgyesi nennt die Widmung ,saftige und schmuselige Rede, [...] welche die schönen und sonst so nützlichen Schriften in deren Anfängen immer ganz verdrecken“" ${ }^{75}$ Medgyesi dedizierte allerdings von achtzehn seiner Schriften sechzehn seinen ,großzügigen Patronen“.

Die eigentliche Kritik der Dedikationspraxis beginnt in Ungarn erst Ende des 18. Jahrhunderts. János Almási Szalai beklagt sich im Vorwort seines 1794 auf eigene Kosten herausgegebenen Szülék kézi-könyve folgendermaßen:

Ama jó formán kipallérozott ízlésű anglus és német nemzeteknél nem igen módi már ma a könyv-ajánlás: mi nálunk is méltán tarthatik ez néhánykor vagy csapodárságnak, vagy pénzkoldulásnak. ${ }^{76}$

Szalai beschreibt genau das Phänomen, das diese Forschung bestätigt. Die finanzielle Unabhängigkeit des Künstlers, die der Dedikationspraxis ein Ende setzt, ist in Ungarn erst viel später als in vielen anderen europäischen Ländern gegeben. Grund dafür ist die verspätete Entwicklung des gesellschaftlichen Umfelds und damit die fehlende Institutionalisierung der Künste. Dies hat zur Folge, dass die barocke Form und Funktion der Widmung in Ungarn länger Bestand hat und erst am Anfang beziehungsweise um die Mitte des 19. Jahrhunderts aufgehoben wird.

\title{
Anmerkungen
}

1 Borsa, Gedeon / Hervay, Ferenc (Hrg.): Régi Magyarországi Nyomtatványok (RMNy). II. Budapest 1983. Sowie Heltai, János (Hrg.): Régi Magyarországi Nyomtatványok. III. Budapest 2000 .

2 Vgl. Gulyás, Pál: A könyvkiadás Magyarországon a XVI-XVIII. században (1527-1773). In: Magyar Könyvszemle 1944, S. 100.

3 U.a.: Walchius, Georgius: Christophori Cellarii epistolae selectiores et praefationes conlegit Jo. qui et copiosiorem diatriben de dedicationibus librorum veterum latinorum paemisit. Leipzig 1715. 
4 U.a.: Heumann, Christoph August: Conspectus Reipublicae literariae sive ad historiam iuventuti studiosae aperta. Hannover 1718; Janus, Daniel Frieder: De Fatis Dedicationum Librorum. Wittenberg 1718; Tackius, Fridericus Petrus: Commentatio historia et literaria de dedicationibus librorum. Wittenberg 1733.

5 Genette, Gérard: Paratexte. Das Buch vom Beiwerk des Buches. Frankfurt, New York 1992.

6 U.a.: Kreimeier, Klaus / Stanitzek, Georg: Vorwort. In: Paratexte in Literatur, Film, Fernsehen. Berlin 2004; Frieder von Ammon / Herfried Vögel (Hrg.): Die Pluralisierung des Paratextes in der frühen Neuzeit. Theorie, Formen, Funktionen. Berlin 2007; Demberck, Till: Texte rahmen. Grenzregionen literarischer Werke im 18. Jahrhundert (Gottsched, Wieland, Moritz, Jean Paul). Berlin, New York 2007; Jürgensen, Christoph: „Der Rahmen arbeitet“. Paratextuelle Strategien der Lektürelenkung im Werk Arno Schmidts. Göttingen 2007.

7 Derrida, Jacques: Die Wahrheit in der Malerei. Wien 1992.

8 U.a.: Dugast, Jacquest: Parerga und Paratexte. Eine Ästhetik des Beiwerks. In: Raulet, Gérard/ Schmidt, Burghart: Vom Parergon zum Labyrinth. Untersuchungen zur kritischen Theorie des Ornaments. Wien, Köln, Weimar 2001, S. 101-110; Wirth, Uwe: Das Vorwort als performative, paratextuelle und parergonale Rahmung. In: Fohrmann, Jürgen: Rhetorik. Figuration und Performanz. Stuttgart 2004, S. 603-628.

9 Graefenhain, Rudolf: De more libros dedicandi apud scriptores Graecos et Romanos obvio. Marburg 1892; Lieberich, Heinrich: Studien zu den Prooemien in der griechischen und byzantinischen Geschichtsschreibung. 1-2. 1889-1899; Peter, Hermann: Der Brief in der römischen Literatur. Litterargeschichtliche Untersuchungen und Zusammenfassungen. In: Abhandlungen der Sächsischen Gesellschaft der Wissenschaften. Leipzig 1901; Engel, Georg: De antiquorum epicorum didactionis librorum pertinentes. Marburg 1910; Ruppert, Johannes: Quaestiones ad historiam dedicationis librorum pertinentes. Leipzig 1911.

10 Schramm, Gabriele: Widmung, Leser und Drama, Untersuchungen zu Form- und Funktionwandel der Buchwidmung im 17. und 18. Jahrhundert. Hamburg 2003.

11 Leiner, Wolfgang: Der Widmungsbrief in der französischen Literatur (1580-1715). Heidelberg 1965.

12 Kettering, Sharon: Patronage in Sixteenth-and Seventeenth-century France. Aldershot 2002.

13 Paoli, Marco: La dedica, storia di una strategia editoriale: Italia, secoli XVI-XIX. Lucca 2009.

14 Dunn, Kevin: Pretexts of Authority. Stanford 1994.

15 Griffin, Dustin: Literary Patronage in England 1650-1800. Cambridge, New York, Melbourne 1996. Zum weiteren: Gurr, Andrew: Politics Patronage and Literature in England 1558-1658. London 1991; Van Houdt, Toun / Papy, Jan / Tournoy, Gilbert / Matheeussen, Constant (Hrg.): Self-presentation and Social Identification. The Rhetoric and Pragmatics of Letter Writing in Early Modern Times. University of Leuven Press 2002, S. 165-182.

16 Hargittay, Emil: Irodalomszemlélet Pázmány előszavaiban és könyvajánlásaiban. In: Bitskey, István, Oláh, Szabolcs (Hrg.): Religió, retorika, nemzettudat régi irodalmunkban. Debrecen 2004, S. 374-383.

17 Onder Csaba: A klasszika virágai (anthologia-praetexta-narratíva). Debrecen 2003.

18 Genette: 1992, S. 115.

19 Genette: 1992, S. 157.

20 „Die Summe der ganzen Büchlein, alle ihre Teile, habe ich in der Vorrede geordnet, um den christlichen Leser zum Lesen zu bewegen. Daher kann verstanden werden, worum es im Buch geht, wozu es anregt und wozu es lehrt, sodass mit umso größerer Freude und größerem Fleiß auf anständig erklärte Lektüre zugegriffen werden kann" (eigene Übersetzung). Bellényi, Zsigmond: Szent Hieronymus Savanarola elmélkedései. Kassa 1618, S. (4)v. OSZK, FM2 551. (RMNy II. 1155.)

21 Cicero, Marcus Tullius: De inventione. Hrg. Theodor Nüßlein. Düsseldorf 1998. 1, IV S. 6. 
22 Onder: 2003, S. 63.

23 RMNy II. und III.

24 Simon, Gertrud: Untersuchungen zur Topik der Widmungsbriefe mittelalterlicher Geschichtsschreiber bis zum Ende des 12. Jahrhunderts. In: Archiv für Diplomatik. Schriftgeschichte, Siegel- und Wappenkunde. 1958, S. 136-138.

25 Geleji Katona, István: Váltság Titka. Várad 1645. (RMNy III. 2124.)

26 Vgl.: Simon: 1985, S. 136-138.

27 Komjáthi, Benedek: Epistolae Pauli lingua Hungarica donatae. Az szent Pál levelei magyar nyelven. Krakkó 1533. (RMNy I. 13.)

28 „Eure durchlauchtigen, gnädigen, hochgeborenen Herren, um die Gründe aufzuzählen, warum ich dieses Büchlein nicht nur Ungarisch beibrachte, sondern auch unter Euren gnädigen und würdigen Namen herauszugeben nicht zögerte [...] wäre dieses Büchleins wegen ihrer Winzigkeit ungeeignet, da so die Vorrede unnötig in die Länge gezogen würde. Doch - über das Weitere zu schweigen - sei meine eifrige Liebe zu Eurer Gnaden und zu unserem Land Grund genug dafür.“ (eigene Übersetzung) Bökényi, Filep János: Mennyei lámpás. Az nemes Ugocsa vármegyének tekéntetes, nagyságos, nemes és nemzetes Urainak. Utrecht 1652, S. $(*) 2^{\mathrm{v}}-(*) 3^{\mathrm{r}}$. OSZK, $\mathrm{FM}^{2}$ 1314. (RMNy III. 2450.)

29 Bohse, August: Talanders getreuer Wegweiser zur Teutschen Rede-Kunst und Briefverfassung. Leipzig 1692, S. 317-338.

30 Morhof, Daniel Georg: Polyhistor, Literarius, philosophicus, et practicus. Lübeck 1714, S. 294-295, 696-697.

31 Neukirch, Benjamin: Anweisung zur Teutschen Briefen. Leipzig 1727, S. 253-257.

32 Harsdörffer, Georg Philipp: Der Teutsche Secretarius. Nürnberg 1656, S. 65-68.

33 Der Spathe [Stieler, Kaspar]: Der Allzeitfertige Secretarius. Nürnberg 1679, S. 1373-1374.

34 Stockhausen, Johann Christoph: Grundsätze wohleingerichteter Briefe. Wien 1766, S. 334-348.

35 Zu der Aufbau deutschsprachiger Dedikationen siehe Leiner: 1965, S. 95-97.

36 Einteilung nach Bohse: 1692, S. 319ff.

37 Curtius, Ernst Robert: Europäische Literatur und lateinisches Mittelalter. Tübingen 1993 , S. 189.

38 Quintilianus, Marcus Fabius: Szónoklattan. Hrg. Adamik, Tamás. Budapest 2008, S. 247-250. [III, 7, 10-25.] Vgl.: Lausberg, Heinrich: Handbuch der literarischen Rhetorik. I-II. München 1973, I, S. 133.

39 Leiner: 1965, S. 51-54.

40 „,in seinen Adern fließt blaues Blut“ (eigene Übersetzung).

41 „fürstlicher Ruf des Geschlechts Ihrer Majestät“" (eigene Übersetzung).

42 „das Geschlecht Ihrer Majestät glänzt mit der königlichen Glorie“ (eigene Übersetzung).

43 "Nicht die Abstammung, sondern die Taten zeugen die Ehre“ (eigene Übersetzung). Zitiert nach Leiner: 1965, S. 51-54.

44 „,vorzüglich in Pietas und Kampfgeschick“ (eigene Übersetzung). IV. 403. Zitiert nach: Curtius 1993, S. 189.

45 „Ich habe Eure christliche Frömmigkeit und Gnade sowie Eure derartige Überzeugung des wahren Glaubens gehört und verstanden, und nachdem ich Eure Majestät kennen lernte, sogar selbst sehen konnte, dass in solchen Fällen Eure Majestät sich vor nichts fürchtet, und wenn es gewünscht wäre, für Euren Glauben und Eure Religion sogar zu sterben bereit wäre." (eigene Übersetzung). Kecskeméti, C. János: Az pápisták között és mi közöttünk vetélkedésre vettetett három fó articulusokról. Ungvár 1619. Epistola dedicatoria, S. )o(4 ${ }^{\mathrm{r}}$. OSZK, RMK I. 519. (RMNy II. 1256.). 
„Gott hat Dich, Gnädige Frau, mit so viel Gelehrsamkeit beschenkt, dass du die Heilige Schrift sogar selbst lesen kannst, was einem Weibe sicherlich größere Zierde ist, als eine auf ihrer Stirn funkelnde Krone oder auf ihren Fingern glitzernde Diamanten" (eigene Übersetzung). Samarjai, János: Magyar harmónia. Pápa, 1628. Epistola dedicatoria, S. $2^{\mathrm{r}-\mathrm{v}}$. OSZK, FM2 571. (RMNy II. 1419.).

47 Moore, Cornelia N.: Erbauungsliteratur als Gebrauchsliteratur für Frauen im 17. Jahrhundert. Leichpredigten als Quellen weiblicher Lesegewohnheiten. In: Veit, P., Bödeker, H., Chaix, G.: Umgang mit dem religiösen Buch. Studien zur Geschichte des religiösen Buches in Deutschland und Frankreich in der frühen Neuzeit. Göttingen 1991, S. 291-311.

48 „Welch Gutes Gottes Gnade in Dir und mit Dir bewirkt hat, zeigt das Bild des neunten Herzens, in dem der himmlische Bräutigam Blumen verstreut, jene Blumen, welche die viele und schöne Vollkommenheit deiner Taten sind, mit denen der Heilige Geist deine Seele ausgeschmückt, und die nach der Sonne drehenden gelben Blume der Liebe, den Balsam der Frömmigkeit, die Lilie der Reinheit, die rote Rose der Tugend, das Maiglöckchen des genügsamen Redens, die Krauseminze der Frömmigkeit, den Ysop der Demut, die Nelke der Stärke, den Rosmarin der Geduld, den Buschbaum der Beharrlichkeit und weitere wunderbare Blumen der vollkommenen Schönheit in Dich gepflanzt hat“ (eigene Übersetzung). Hajnal Mátyás: Az Jézus szivet szeretö sziveknek ájtatosságára szives képekkel kiformáltatott és azokrul való elmélkedésekkel és imádságokkal megmagyaráztatott könyvecske. Bécs 1629. Az nemzetes és nagyságos gróf Bedegi Nyáry Krisztina asszonynak. In: Régi magyar költők tára. XVII/7. Budapest 1877-1930, S. 479. (RMNy II. 1422.).

49 RMNy III. 1942.

50 RMNy III. 1772.

51 RMNy III. 2012.

52 RMNy III. 1835.

53 RMNy II. 1532.

54 RMNy III. 1419.

55 „Zu Recht kann ich Sie, Gnädige Frau, als glückliche bezeichnen, die von Gott mit so einem großzügigen und weisen, gnädigen Mann und solchen frommen Söhnen gesegnet wurde, und die in sich auch so viele seelische Geschenke trägt, wie Gelehrsamkeit in der Religion, Beharrlichkeit im Glauben, heiße Liebe zu den Worten Gottes, Frömmigkeit im Gebet und fleißiges Bestreben nach der Verbreitung von Gottes Ruhm, womit Sie sowohl für Ihre Söhne, als auch für Ihre Schwiegertöchter, sowohl in Ihrem Leben, als auch nach Ihrem Tod als gutes Beispiel dienen können“ (eigene Übersetzung). Geleji Katona, István: $A$ váltság titkának második volumenje. Várad 1647. Ajánló elöbeszéd a Váltság munkájának két föbb részeiröl. S. $\mathrm{h}^{\mathrm{r}}$. OSZK, FM ${ }^{2}$ 85. (RMNy III. 2197.)

56 Vgl.: Gleixner, Ulrike: Pietismus und Bürgertum. Eine historische Anthropologie der Frömmigkeit Würtenberg, 17-19. Jahrhundert. Göttingen 2005, S. 292.

57 Vgl.: Modrow, Irena: Adelige Frauen im Pietismus. In: Weinzierl, Michael (Hrg.): Individualisierung, Rationalisierung, Säkularisierung. Neue Wege der Religionsgeschichte. S. 187-200. (Wiener Beiträge zur Geschichte der Neuzeit 22.)

58 Mehr zum Thema: Pesti, Brigitta: Lektüre der Glaubensicherung: Erbauungsliteratur und das weibliche Lesepublikum im 17. Jahrhundert. In: Wiener Beiträge zur finnougristischen Forschung. 2009; Gleixner, Ulrike: Pietismus und Bürgertum. Eine historische Anthropologie der Frömmigkeit. Göttingen 2005; Medick, Hans: Buchkultur und lutherischer Pietismus. In: Vierhaus, Rudolf(Hrg.): Frühe Neuzeit-Frühe Moderne? Forschungen zur Vielseitigkeit von Übergangsprozessen. Göttingen 1992; Moore: 1991.

59 Zitiert nach Simon: 1958, S. 109. 
60 Ehrenzeller, Hans: Studien zur Romanvorrede von Grimmelshausen bis Jean Paul. Bern 1955, S. 34-37.

61 Illyésházi, Gáspár: Kézben viselö könyv. Debrecen 1639. (RMNy III. 1763.); Nádasdy, Pál: Áhitatok és buzgó imádságok. Csepreg 1631. (RMNy II. 1494.); Madarász, Márton: Kegyességnek mindennapi gyakorlása. Lőcse 1652. (RMNy III. 2421.); sowie Draskovich, János: Horologii principium, azaz az fejedelmek órájának második könyve. Graz 1610. (RMNy II. 994.).

62 Alvinczi, Péter: Itinerarium catholicum. Debrecen 1616. (RMNy II. 1104.); Szenczi Csene, Péter: Confessio Helvetica. Oppenheim 1616. (RMNy II. 1115.); Péter Pázmány an alle wahren Christen: Kempis Tamásnak Krisztus követésérül négy könyvei. Bécs 1638. (RMNy III. 1713.).

63 Vásárhelyi, Gergely: Világ kezdetitől fogva jóságos és gonosz cselekedetek summái. Kassa 1623. (RMNy II. 1289.); Alvinczi, Péter: Itinerarium catholicum. Debrecen 1616. (RMNy II. 1104.); Zrínyi, Miklós: Szigeti veszedelem. Bécs 1651. Hrg.: Kovács, Sándor Iván. Budapest 2001. (RMNy III. 2360.); Bálint Balassi an die adelige Frauen: Szép magyar komédia. Bártfa 1589.

64 Pázmány, Péter: A római Anyaszentegyház szokásából minden vasárnapokra és egy-nehány innepekre rendelt evangeliomokrúl prédikációk. Pozsony, 1636. (RMNy II. 1659.).

65 Pázmány, Péter: Keresztyéni felelet. Graz, 1607. (RMNy II. 961.); Csepregi mesterség. Bécs 1614. (RMNy II. 1061.) Dissertatio, an unum aliqvid ex omnibus Lutheranis dogmatibus. Pozsony 1631. (RMNy III. 1512.)

66 Leiner: 1965, S. 222.

67 Burke, Peter: The Italian Renaissance. Culture and Society in Renaissance Italy. Cambridge 1987. Vgl.: Az olasz reneszánsz. Kultúra és társadalom Itáliában. Budapest 1999, S. 105-107.

68 Haferkorn, Hans J.: Zur Entstehung der bürgerlich-literarischen Intelligenz und des Schriftstellers in Deutschland zwischen 1750 und 1800. In: Bernd, Lutz (Hrg.): Literaturwissenschaft und Sozialwissenschaften. 3. Stuttgart 1974, S. 206.

69 Leiner: 1965, S. 456.

70 Leiner: 1965, S. 269-283 (Die Einstellung der Autoren zur Widmungsmode); Schramm: 2003. S. 163-176 (Zur Funktion der Widmung - Kritik der Schutz); Richardson: 1999. S. 49-77 (Patronage, contracts and privileges).

71 Fratta, Giovanni: Della dedicatione de 'Libri con la correzion dell 'Abuso in questa materia introdotto. Venedig 1590.

72 Richardson: 1999, S. 56-58

73 Leiner: 1965, S. 26.

74 Der Spathe [Stieler, Kaspar]: Teutsche Sekretariatkunst. Weimar 1673, S. 582.

75 „nagy kerülő cifrás és hízelkedő beszéd, mellyel sok szép és egyébként hasznos írások az ő kezdetekben meg szoktak mocskoltatni“. Medgyesi, Pál: Praxis pietatis. Várad 1643. Ajánló levél, S. (2) ${ }^{\mathrm{r}}-(3)^{\mathrm{r}}$. ELTE EK, RMK I. 145:1. (RMNy III. 2042.)

76 „Bei der englischen und deutschen Nation, mit schön veredeltem Geschmack, ist die Buchdedikation gar nicht mehr in Mode: bei uns kann es zu recht für Flatterhaftigkeit oder Bettelei gehalten werden“ (eigene Übersetzung). Zitiert nach Trócsányi, Zoltán: Az ajánlások történetéhez. Magyar Könyvszemle 1938, 1, S. 77-80. 